\title{
Impact of hypokalemia on peritonitis in peritoneal dialysis patients: a systematic review
}

\author{
Kentaro Nakai ${ }^{1,2}$, Kei Saito ${ }^{1,2}$, Hideki Fujii ${ }^{1}$ and Shinichi Nishi ${ }^{*}$
}

\begin{abstract}
s
Background: Hypokalemia is a common electrolyte disorder in peritoneal dialysis patients. Some studies showed the association of serum potassium levels with all-cause and cardiovascular mortality and infection. This review aims to clarify the relationship of hypokalemia and peritonitis in peritoneal dialysis.

Methods: The MEDLINE and Cochrane Library databases were searched for articles published from 1990 to May 2016. The following search terms were used: hypokal(a)emia, potassium, peritoneal dialysis, peritonitis, and infection. Additional studies were identified by hand searching through references and using the MEDLINE-related articles option. Two investigators independently selected studies using predefined criteria and assessed each study's quality using the Newcastle-Ottawa Quality Assessment Scale.

Results: A total of 159 abstracts were identified and 6 trials were included in the systematic review $(n=3613)$. One national prospective study and two retrospective single-center studies indicated that hypokalemia increases the risk of peritonitis, whether two single-center studies indicated otherwise. One case-control study indicated that lower potassium level was associated with a poor therapeutic outcome in peritonitis.

Conclusion: Convincing clinical trial data are unavailable to show the association of hypokalemia with peritonitis in peritoneal dialysis patients, and we need to clarify whether the therapeutic intervention to normalize serum potassium levels decreases the risk of peritonitis and infection-related mortality in peritoneal dialysis patients.
\end{abstract}

Keywords: Hypokalemia, Infection, Peritoneal dialysis, Peritonitis, Potassium

\section{Background}

Peritonitis is one of the specific and major complications in peritoneal dialysis, which does not occur in hemodialysis. It is well known that peritonitis is the major reason for withdrawal of peritoneal dialysis $[1,2]$. Candidates for renal replacement therapy often hesitate to select peritoneal dialysis due to fear of the possibility of peritonitis.

For reducing the risk of peritonitis, various strategies are indicated in position statement of the international society for peritoneal dialysis, such as prophylactic antibiotics at catheter insertion and before invasive gastrointestinal procedures, patient training program, and avoidance of constipation [3]. In spite of those

\footnotetext{
* Correspondence: snishi@med.kobe-u.ac.jp

${ }^{1}$ Division of Nephrology and Kidney Center, Kobe University Graduate School of Medicine, 7-5-2, Kusunoki-cho, Chuo-ku, Kobe, Hyogo 650-0017, Japan Full list of author information is available at the end of the article
}

efforts of prevention of peritonitis, peritoneal dialysisassociated peritonitis rates have not been reduced sufficiently $[1,4]$. Even the introduction of disconnect systems has not been dramatically improved the risk of peritonitis [5, 6].

How can we reduce the risk of peritonitis more? Although strong evidence does not exist yet, hypoalbuminemia, vitamin D insufficiency, depression, and hypokalemia are reported as the residual modifiable risk factors for peritonitis [3, 7]. Hypokalemia is common, but insufficiently studied, electrolyte disorder that occurs in patients undergoing peritoneal dialysis. This review aims to clarify the relationship between hypokalemia and peritonitis in peritoneal dialysis. 


\section{Methods}

The review protocol has been registered in PROSPERO International Prospective Register of Systematic Reviews (CRD42016039950).

\section{Search strategy and selection criteria}

The MEDLINE and Cochrane Library databases were searched for articles published from 1990 to May 2016. The following search terms were used: hypokal(a)emia, potassium, peritoneal dialysis, peritonitis, and infection. Additional studies were identified by manually searching through references and using the "related articles" option in MEDLINE. Eligible studies or studies in which eligibility criteria were unclear after the title and abstract screening underwent full-text review. A study that met the following criteria was included: (1) the study compared the clinical outcomes of peritoneal dialysis patients with or without hypokalemia and (2) the study reported the incidence of peritonitis. Two reviewers (K.N. and K.S.) assessed the criteria for all studies identified for full-text review.

\section{Data extraction and quality assessment}

We extracted characteristics of the study populations (sample size, age, sex, prevalence of diabetes mellitus, and other clinical information), characteristics of the studies (study design, source of cohort, and follow-up periods), and outcome characteristics. According to the Newcastle-Ottawa scale $[8,9]$, the quality of the included studies was scored independently by two investigators (K.N. and K.S.), with disagreements resolved by consensus. The systematic review of the literature was performed according to PRISMA guidelines [10].

\section{Results}

Figure 1 showed the steps in study selection for this review. A total of 159 abstracts were identified, and six trials were included in the systematic review $(n=3613)$. Table 1 shows details of the five cohort studies that were included in the qualitative review. One study, not listed in Table 1, included 60 patients with 120 episodes of peritonitis and compared persistent episodes with usual episodes responding to antibiotic therapy within $96 \mathrm{~h} \mathrm{[11].}$

\section{Risk-of-bias and quality assessment}

All of the cohort studies defined hypokalemia as serum potassium levels below $3.5 \mathrm{mEq} / \mathrm{L}$ and controls as normokalemic subjects in the same population. The study by Ribeiro et al. [12] was well designed for our purposes and performed a propensity score analysis to account for any underlying differences between patients with a timeaveraged potassium under $3.5 \mathrm{mEq} / \mathrm{L}$ and others. Although the study with the lowest risk of bias by $\mathrm{Su}$ et al. [13] excluded cases with acute complication including peritonitis occurred in the previous month, Su et al. [13] and Chuang et al. [14] had no description about the history of peritonitis. Peritonitis was not present at the start of the other three studies [12, 15, 16], which included only incident cases of peritoneal dialysis (Table 2). Ribeiro et al. [12] performed a national prospective cohort study with complete follow-up, whereas lost follow-up rate was not described in two retrospective studies $[15,16]$. One case-control study defined controls as responding episodes from partially duplicated subjects with persistent cases [11]. In this study, the relationship between therapeutic response and serum potassium levels was adjusted by age and serum albumin levels, but specified cutoff level of potassium levels was not described.

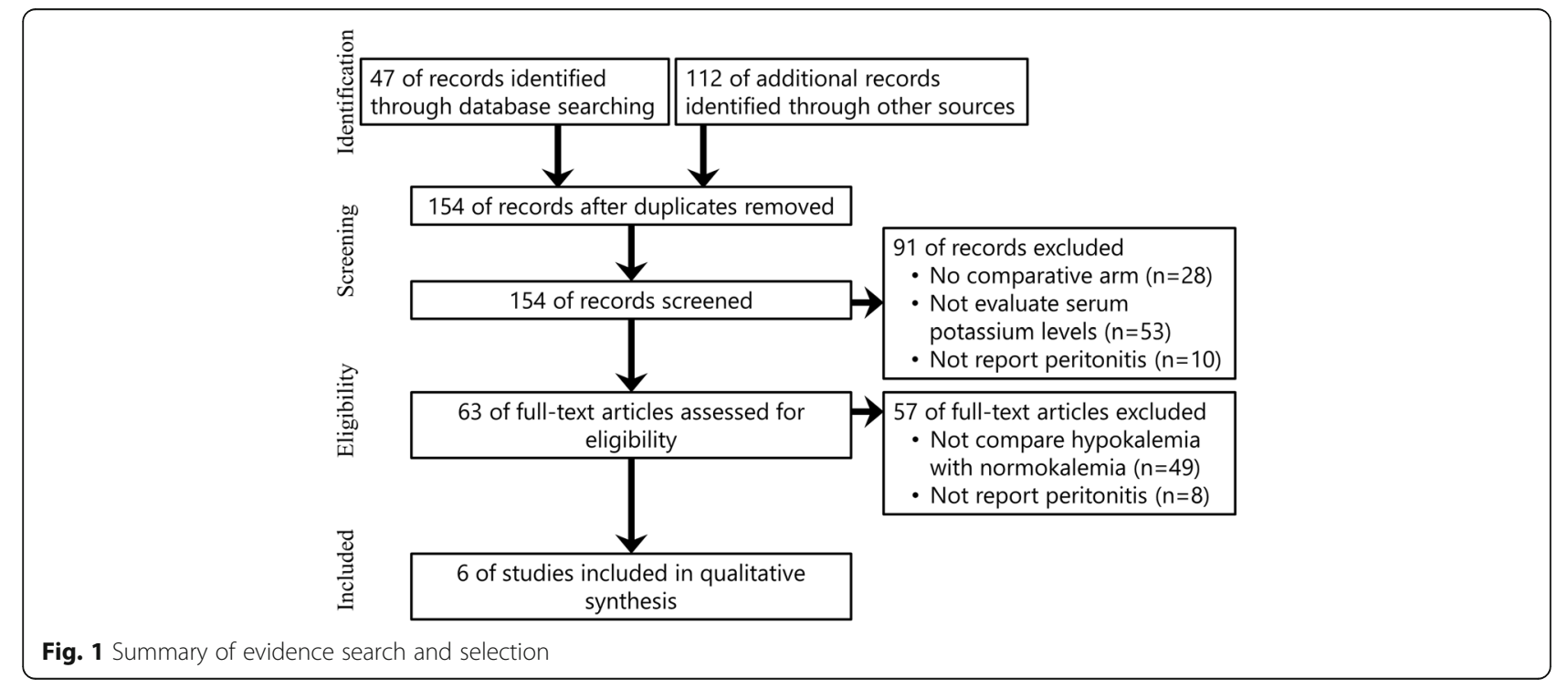


Table 1 Details of cohort studies included in this analysis

\begin{tabular}{|c|c|c|c|c|c|c|c|c|}
\hline $\begin{array}{l}\text { Study and year } \\
\text { (reference) }\end{array}$ & Design & $\begin{array}{l}\text { Sample } \\
\text { size }\end{array}$ & Population & $\begin{array}{l}\text { Age } \\
(y .0)\end{array}$ & $\begin{array}{l}\text { Men } \\
(\%)\end{array}$ & $\begin{array}{l}\mathrm{DM} \\
(\%)\end{array}$ & Follow-up period & $\begin{array}{l}\text { Peritonitis rate (patient } \\
\text { month per episode) }\end{array}$ \\
\hline Ribeiro, 2015 [12] & $\begin{array}{l}\text { Prospective } \\
\text { cohort }\end{array}$ & 1817 & $\begin{array}{l}\text { National } \\
\text { wide }\end{array}$ & 62.7 & 37.0 & 45.2 & Not described & Not described \\
\hline Fan, 2014 [16] & $\begin{array}{l}\text { Retrospective } \\
\text { cohort }\end{array}$ & 1117 & Single center & 48.3 & 58.7 & 22.6 & 26.1 months & 60.0 \\
\hline $\begin{array}{l}\text { Liawnoraset, } 2011 \\
\text { [15] }\end{array}$ & $\begin{array}{l}\text { Retrospective } \\
\text { cohort }\end{array}$ & 318 & Single center & 49.9 & 50.9 & 34.9 & $\begin{array}{l}3262.2 \text { patient- } \\
\text { months }\end{array}$ & 25.5 \\
\hline Su, 2012 [13] & $\begin{array}{l}\text { Prospective } \\
\text { cohort }\end{array}$ & 158 & Single center & 62.46 & 51.3 & 29.7 & 22.09 months & 75.87 \\
\hline Chuang, 2009 [14] & $\begin{array}{l}\text { Retrospective } \\
\text { cohort }\end{array}$ & 140 & Single center & 47.8 & 39.3 & 18.4 & $\begin{array}{l}1961 \text { patient- } \\
\text { months }\end{array}$ & 30.6 \\
\hline
\end{tabular}

\section{Trial characteristics and outcome}

A summary of study characteristics is shown in Table 1. A Brazilian national cohort study [12] enrolled older subjects and higher prevalence of diabetes than the other singlecenter cohort studies. In this study, hypokalemia based on time-average potassium levels, measured monthly in all patients throughout the whole observational period, had a higher risk for time to first peritonitis episode compared to propensity-matched patients (Fig. 2). Chuang et al. [14] showed that the prevalence of peritonitis was significantly higher in patients with at least one episode of hypokalemia than those with normokalemia (6.9 vs. $2.1 \%$, respectively, $p<0.001)$. Although the association was not adjusted for any confounders, there was no correlation between peritonitis and age, body mass index, and gender, with or without diabetes mellitus, as well as comorbidity. Liawnoraset [15] showed that patients with hypokalemia had a lower mean peritonitis-free survival time than those without hypokalemia in subgroup univariate analysis (16.2 vs. 28.1 months, $p<0.05)$. Similarly, patients $>60$ years old with hypoalbuminemia had a lower mean peritonitisfree survival time. However, the association of hypokalemia and peritonitis was not adjusted for any confounders, including age and serum albumin levels. Fan et al. [16] reported that hypokalemia based on the potassium levels, measured within 1 to 3 months of the start of peritoneal dialysis therapy, was not associated with the risk for the first episode of peritonitis. Su et al. [13] also showed that hypokalemia based on the potassium levels, measured only at the time of symptoms survey, was not associated with a first peritonitis episode during the follow-up period. Murata et al. [11] indicated that lower potassium level, based on the four-month mean immediately before the episode of peritonitis, was associated with a poor therapeutic response of peritonitis in case-control study.

\section{Discussion}

The association between hypokalemia and peritonitis in patients undergoing peritoneal dialysis is feasible but currently inconclusive. Because common effect indicators could not be derived from the information described in the papers, some studies were excluded from Fig. 2. The results were controversial and insufficiently adjusted for confounding factors contributing to the association between peritonitis and hypokalemia. Occasionally, hypokalemia has close links with poor dietary intake, malnutrition, and poor general condition (Fig. 3), so that the association with peritonitis also may depend on such status. Ultimately, we must determine whether the therapeutic interventions used to normalize serum potassium levels, such as the administration of potassium chloride and adjustment of food or dialysate, decrease the risk of peritonitis and infection-related mortality in patients undergoing peritoneal dialysis. In fact, hypokalemia is so common in peritoneal dialysis that several attempt to adjust serum potassium levels in such patients $[17,18]$. The effectiveness of spironolactone for peritoneal dialysis patients was evaluated in

Table 2 Risk of bias in included cohort studies

\begin{tabular}{|c|c|c|c|c|c|c|c|c|}
\hline $\begin{array}{l}\text { Study and year } \\
\text { (reference) }\end{array}$ & Representativeness & $\begin{array}{l}\text { Selection } \\
\text { of controls }\end{array}$ & $\begin{array}{l}\text { Exposure } \\
\text { ascertained }\end{array}$ & $\begin{array}{l}\text { Not present } \\
\text { at outset }\end{array}$ & Comparability & $\begin{array}{l}\text { Outcome } \\
\text { assessment }\end{array}$ & $\begin{array}{l}\text { Duration } \\
\text { of follow-up }\end{array}$ & $\begin{array}{l}\text { Adequacy } \\
\text { of follow-up }\end{array}$ \\
\hline Ribeiro, 2015 [12] & 1 & 1 & 1 & 1 & 2 & 1 & 0 & 1 \\
\hline Fan, 2014 [16] & 1 & 1 & 1 & 1 & 2 & 1 & 1 & 0 \\
\hline Liawnoraset, 2011 [15] & 1 & 1 & 1 & 1 & 0 & 1 & 1 & 0 \\
\hline Su, 2012 [13] & 1 & 1 & 1 & 1 & 2 & 1 & 1 & 1 \\
\hline Chuang, 2009 [14] & 1 & 1 & 1 & 0 & 0 & 1 & 1 & 1 \\
\hline
\end{tabular}

The Newcastle-Otawa Scales were used to assess risk of bias for the cohort studies. Each domain was rated on a maximum of one star, except comparability which can be given up to two stars. 0 , high risk of bias or no description; 1 or 2 , low risk of bias 


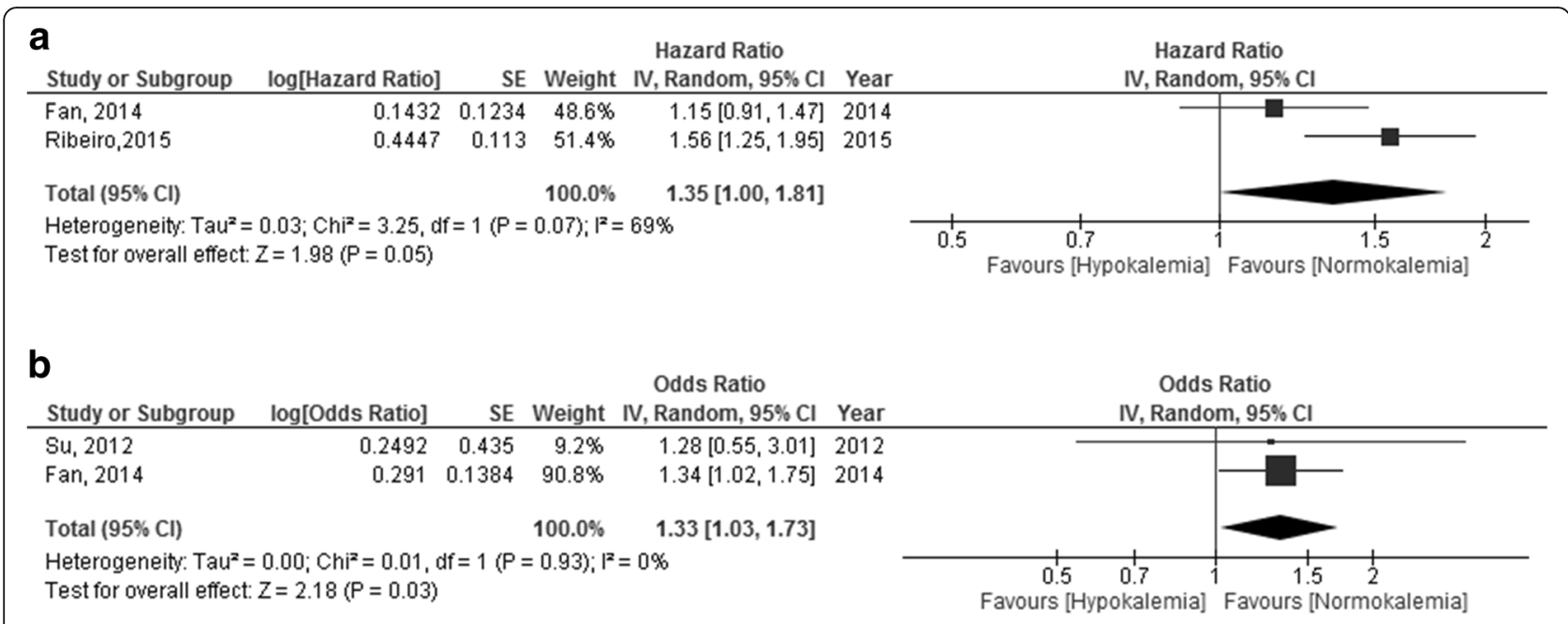

Fig. 2 Comparison of the time to first peritonitis episode (a) and the first peritonitis episode (b) with and without hypokalemia

several surveys $[17,19,20]$; however, serum potassium levels were not influenced by spironolactone in two studies $[17,19]$. Ito, et al. [20] showed that serum potassium levels were increased in patients with spironolactone, but the prevalence of hypokalemia and peritonitis were comparable between patients with and without spironolactone. Yi et al. [21] showed the effect of glucose-free icodextrin on the improvement of hypokalemia compared with conventional glucose-containing dialysate, possibly through an enhanced nutritional status and an intracellular potassium shift. Spital et al. [18] reported the effectiveness of acute potassium loading via the dialysate in peritoneal dialysis patients; however, the influence to peritonitis was not studied. The risk of potassium supplements should also be considered. For example, in patients with chronic heart failure, potassium supplements could increase hospitalization because of worsening heart failure against all expectations [22].

Several mechanisms can be speculated for hypokalemia to promote peritonitis in peritoneal dialysis (Fig. 3 ). At first, hypokalemia may induce gastrointestinal dysmotility [23] and intestinal bacterial overgrowth [24]. As a result, the translocation of bacteria from the intestine to peritoneal cavity may cause peritonitis. Moreover, potassium chloride supplementation decreased pain intensity and erythrocyte sediment rate in patients with rheumatoid arthritis [25] and may have the protective effect on inflammatory response [26].

\section{Conclusions}

Our review could not find a consistent correlation between hypokalemia and peritonitis in patients with

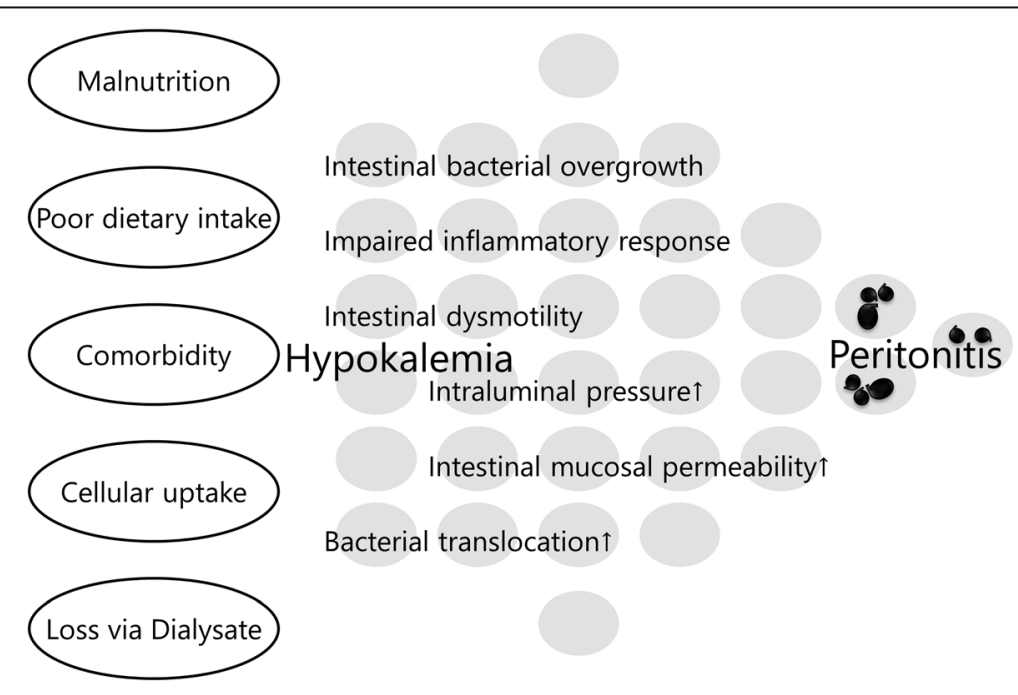

Fig. 3 Putative association of hypokalemia with peritonitis in peritoneal dialysis patients 
peritoneal dialysis. We did not identify sufficient data and studies with low-risk bias to clarify the association. To confirm the causal connection, further well-designed studies are needed whether the adjustment of potassium levels can improve the risk of peritonitis in peritoneal dialysis patients with hypokalemia.

\section{Acknowledgements}

The authors wish to acknowledge contributions to this work from Daisuke Kanai and Atsushi Shirai for secure data collection and helpful discussion. This work was partly presented at the ASN Kidney Week 2016 Annual Meeting, November 15-20 in Chicago, IL.

\section{Funding}

Not applicable.

\section{Availability of data and materials}

Data sharing not applicable to this article as no datasets were generated or analyzed during the current study.

\section{Authors' contributions}

KN contributed to the research idea and study design. KN and KS contributed to the data acquisition and data analysis/interpretation. HF and SN contributed to the supervision or mentorship. Each author contributed important intellectual content during manuscript drafting or revision and accepts accountability for the overall work by ensuring that questions pertaining to the accuracy or integrity of any portion of the work are appropriately investigated and resolved. All authors approved the final version of the submitted manuscript.

\section{Ethics approval and consent to participate}

Not applicable.

\section{Consent for publication}

Not applicable.

\section{Competing interests}

The authors declare that they have no competing interests.

\section{Publisher's Note}

Springer Nature remains neutral with regard to jurisdictional claims in published maps and institutional affiliations.

\section{Author details}

'Division of Nephrology and Kidney Center, Kobe University Graduate School of Medicine, 7-5-2, Kusunoki-cho, Chuo-ku, Kobe, Hyogo 650-0017, Japan. ${ }^{2}$ Department of Nephrology and Kidney Center, Kakogawa Central City Hospital, 439, Honmachi, Kakogawa-cho, Kakogawa, Hyogo 675-8611, Japan.

Received: 12 April 2017 Accepted: 22 August 2017

Published online: 23 November 2017

\section{References}

1. Mizuno M, Ito $Y$, Suzuki $Y$, et al. Recent analysis of status and outcomes of peritoneal dialysis in the Tokai area of Japan: the second report of the Tokai peritoneal dialysis registry. Clin Exp Nephrol. 2016;20(6):960-71. doi:10.1007/ s10157-016-1249-9.

2. Verger $C$, Ryckelynck J-P, Duman $M$, et al. French peritoneal dialysis registry (RDPLF): outline and main results. Kidney Int Suppl. 2006;70(103):S12-20. doi:10.1038/sj.ki.5001911

3. Piraino B, Bernardini J, Brown E, et al. ISPD position statement on reducing the risks of peritoneal dialysis-related infections. Perit Dial Int. 2011;31(6): 614-30. doi:10.3747/pdi.2011.00057

4. Brown MC, Simpson K, Kerssens JJ, Mactier RA. Peritoneal dialysis-associated peritonitis rates and outcomes in a national cohort are not improving in the post-millennium (2000-2007). Perit Dial Int. 2011;31(6):639-50. doi:10.3747/ pdi.2010.00185.

5. Strippoli GFM, Tong A, Johnson D, Schena FP, Craig JC. Catheter-related interventions to prevent peritonitis in peritoneal dialysis: a systematic review of randomized, controlled trials. J Am Soc Nephrol. 2004;15(10):2735-46. doi: 10.1097/01.ASN.0000141463.95561.79.

6. Piraino $B$, Sheth $H$. Peritonitis - does peritoneal dialysis modality make a difference? Blood Purif. 2010;29(2):145-9. doi:10.1159/000245641.

7. Piraino B. Insights on peritoneal dialysis-related infections. Contrib Nephrol. 2009:163:161-8. doi:10.1159/000223795.

8. Wells GA, Shea B, O'Connel D, et al. The Newcastle-Ottawa Scale (NOS) for assessing the quality of nonrandomised studies in meta-analyses. http://www. ohri.ca/programs/clinical_epidemiology/oxford.asp. Accessed 2 Jan 2017.

9. Stang A. Critical evaluation of the Newcastle-Ottawa scale for the assessment of the quality of nonrandomized studies in meta-analyses. Eur J Epidemiol. 2010;25(9):603-5. doi:10.1007/s10654-010-9491-z.

10. Liberati A, Altman DGDDG, Tetzlaff J, et al. The PRISMA statement for reporting systematic reviews and meta-analyses of studies that evaluate health care interventions: explanation and elaboration. PLoS Med. 2009;6(7): e1000100. doi:10.1371/journal.pmed.1000100.

11. Murata GH, Fox L, Tzamaloukas AH. Predicting the course of peritonitis in patients receiving continuous ambulatory peritoneal dialysis. Arch Intern Med. 1993;153(20):2317-21.

12. Ribeiro SC, Figueiredo AE, Barretti P, Pecoits-Filho R, de Moraes TP. Low serum potassium levels increase the infectious-caused mortality in peritoneal dialysis patients: a propensity-matched score study. PLoS One. 2015;10(6):e0127453. doi:10.1371/journal.pone.0127453. Aguilera Al, ed

13. Su CY, Pei J, Lu XH, Tang W, Wang T. Gastrointestinal symptoms predict peritonitis rates in CAPD patients. Clin Nephrol. 2012;77(4):267-74. doi:10. 5414/CN107249.

14. Chuang YW, Shu KH, Yu TM, Cheng CH, Chen CH. Hypokalaemia: an independent risk factor of enterobacteriaceae peritonitis in CAPD patients. Nephrol Dial Transplant. 2009;24(5):1603-8. doi:10.1093/ndt/gfn709.

15. Liawnoraset W. Prevalence and factors affecting peritonitis in CAPD patients in Maharat Nakhon Ratchasima Hospital under universal coverage scheme during 2008-2010: a three-year experience. J Med Assoc Thail. 2011; 94(Suppl 4):S19-24.

16. Fan X, Huang R, Wang J, et al. Risk factors for the first episode of peritonitis in Southern Chinese continuous ambulatory peritoneal dialysis patients. PLoS One. 2014;9(9):e107485. doi:10.1371/journal.pone.0107485. Jia Z, ed

17. Yongsiri S, Thammakumpee J, Prongnamchai S, et al. Randomized, doubleblind, placebo-controlled trial of spironolactone for hypokalemia in continuous ambulatory peritoneal dialysis patients. Ther Apher Dial. 2015; 19(1):81-6. doi:10.1111/1744-9987.12219.

18. Spital A, Sterns RH. Potassium supplementation via the dialysate in continuous ambulatory peritoneal dialysis. Am J Kidney Dis. 1985;6(3):173-6.

19. Taheri S, Mortazavi M, Pourmoghadas A, Seyrafian S, Alipour Z, Karimi S. A prospective double-blind randomized placebo-controlled clinical trial to evaluate the safety and efficacy of spironolactone in patients with advanced congestive heart failure on continuous ambulatory peritoneal dialysis. Saudi J Kidney Dis Transplant. 2012;23(3):507-12.

20. Ito $Y$, Mizuno M, Suzuki $Y$, et al. Long-term effects of spironolactone in peritoneal dialysis patients. J Am Soc Nephrol. 2014;25(5):1094-102. doi:10. 1681/ASN.2013030273

21. Yi J-H, Park J-I, Choi H-Y, Lee H-Y, Han S-W, Kim H-J. Icodextrin improves the serum potassium profile with the enhancement of nutritional status in continuous ambulatory peritoneal dialysis patients. Electrolyte Blood Press. 2009;7(2):79-86. doi:10.5049/EBP.2009.7.2.79.

22. Ekundayo OJ, Adamopoulos C, Ahmed MI, et al. Oral potassium supplement use and outcomes in chronic heart failure: a propensity-matched study. Int J Cardiol. 2010;141(2):167-74. doi:10.1016/j.ijcard.2008.11.195.

23. Singharetnam W, Holley JL. Acute treatment of constipation may lead to transmural migration of bacteria resulting in gram-negative, polymicrobial, or fungal peritonitis. Perit Dial Int. 1996;16(4):423-5.

24. Shu K-H, Chang C-S, Chuang Y-W, et al. Intestinal bacterial overgrowth in CAPD patients with hypokalaemia. Nephrol Dial Transplant. 2009;24(4):128992. doi:10.1093/ndt/gfn617.

25. Rastmanesh R, Abargouei AS, Shadman Z, Ebrahimi AA, Weber CE. A pilot study of potassium supplementation in the treatment of hypokalemic patients with rheumatoid arthritis: a randomized, double-blinded, placebocontrolled trial. J Pain. 2008;9(8):722-31. doi:10.1016/j.jpain.2008.03.006.

26. Wen W, Wan Z, Ren K, et al. Potassium supplementation inhibits IL-17A production induced by salt loading in human T lymphocytes via p38/MAPK-SGK1 pathway. Exp Mol Pathol. 2016;100(3):370-7. doi:10.1016/j.yexmp.2016.03.009. 